\title{
Three-layer reconstruction of large urethrocutaneous fistulas using scrotal-septal flaps
}

\author{
Yu Zhou, MD; Liang Li, MD; Chuande Zhou, MD; Fengyong Li, MD; Linhai Xie, MD; Senkai Li, MD
}

Department of Hypospadias and Gynecological Plastic Surgery, Plastic Surgery Hospital, Peking Union Medical College, Beiiing, China

Cite as: Can Urol Assoc J 2014;8(11-12):e828-31. http://dx.doi.org/10.5489/cuaj.1983 Published online November 24, 2014.

\section{Abstract}

Introduction: The repair of large urethrocutaneous fistulas (UCFs) commonly involves reconstruction of the urethra, waterproof layer and skin coverage, which deploy different tissues from different flaps. To simplify the multiple procedures, we explored to use one flap (a scrotal-septal flap) to reconstruct three layers in UCF repairing in one stage.

Methods: Between January 2011 and July 2012, 29 patients with large UCFs (ranging from 1.0 to $2.0 \mathrm{~cm}$ ) were treated using scrotal-septal flaps for three-layer reconstruction. Every patient has an unbroken scrotum. The hair follicles in the donor site were destroyed using a radiosurgical knife 2 months before the operation. The flap was divided into three zones, which were flipped, folded, and extended respectively to form the urethra, waterproof layer and skin coverage.

Results: The patients were followed up between 6 to 12 months. No fistula recurrence was observed. All flaps survived, except in one case, in which the distal skin flap was lost but stenosis or fistula did not develop. Two patients underwent second operations to refine the aesthetic results.

Conclusions: The scrotal-septal flap can be transferred in an overturning-folding-advancement fashion and can simultaneously involve the reconstruction of the urethra, waterproof barrier and skin coverage. This is a simple and reliable alternative for large UCFs $(\leq 2 \mathrm{~cm})$ repairing at the penoscrotal junction; however, it cannot be used in patients with a damaged scrotal septum.

\section{Introduction}

Hypospadias surgery has experienced tremendous technical improvements over the last decades, but there is still a high complication rate. ${ }^{1,2}$ Among various complications, urethrocutaneous fistula (UCF) is the most frustrating experience; it is hard to manage, due to the lack of healthy surrounding tissue. Recently, it has been reported that an extra water- proof layer between the urethra and skin is able to improve the success rate and reduce the recurrence of the fistula. ${ }^{3-8}$ Therefore, three-layer reconstruction, including outer cutaneous coverage, waterproof layer and inner urethral layer, has gained popularity in fistula repair.

In the previous reports, the three layers were fabricated using different tissues from different flaps, which made the procedure complex and time-consuming. It would be highly desirable if multiple layer fabrication can be done with one flap. Scrotal septum vascular pedicle flap is an optional flap for repairing UCF with its reliable blood supply. ${ }^{9-10}$ It is an ideal candidate that can provide sufficient tissue for threelayer reconstruction. In this series, we transferred the scrotalseptal flap in an overturning-folding-advancement fashion to reconstruct the three layers simultaneously using one flap in one stage to repair the huge UCFs at penoscrotal junction.

\section{Methods}

From January 2011 to July 2012, 29 patients with a large UCF at the junction of the penis and scrotum were treated with three-layer reconstruction using scrotal-septal flap. Their age ranged from 13 to 46, with a mean age of 23 years. All the patients underwent multistage operations previously in other hospitals (Table 1). The size of the UCF ranged from 1.0 to $2.0 \mathrm{~cm}$, and UCFs were at or close to the junction of the penis and the scrotum. Physical examination revealed normal development of the scrotum, an undamaged scrotal septum, and no obvious stricture at the urethra distal to the fistula.

\section{Operative techniques}

Firstly, hair follicles in the donor site were destroyed using a radiosurgical knife 2 months before the operation.

Intraoperatively, the distal urethra was perfused using a methylene blue saline solution under pressure $(1 \mathrm{~mL}$ of methylene blue and $20 \mathrm{~mL}$ of saline) to determine the num- 


\begin{tabular}{|c|c|c|}
\hline Classification & $\begin{array}{c}\text { No. } \\
\text { patients }\end{array}$ & Medical history \\
\hline $\begin{array}{l}\text { Anterior/middle shaft with } \\
\text { chordee }\end{array}$ & 6 & $\begin{array}{l}\text { Barcat's post meatal } \\
\text { tissues flap }\end{array}$ \\
\hline $\begin{array}{l}\text { Proximal shaft and } \\
\text { penoscrotal type with } \\
\text { chordee }\end{array}$ & 18 & $\begin{array}{l}\text { Duckett's tubularized } \\
\text { preputial flap }\end{array}$ \\
\hline $\begin{array}{l}\text { Scrotal type with severe } \\
\text { chordee }\end{array}$ & 5 & (Multistage) \\
\hline
\end{tabular}

ber and location of the UCFs. Then, the penis was fixed onto the mons pubis to expose the ventral surface of the penis. The scar contracture around the UCF was fully released, and the diameter of the UCF was measured. Multiple UCFs, close to each other, were excised and made as a single large UCF.

A longitudinal flap, with anterior and posterior scrotal vessels as the pedicle, was designed alone the scrotal septum below the UCF and divided into three zones: $\mathrm{A}, \mathrm{B}$, and $\mathrm{C}$ (Fig. 1, part A). The width of the flap was designed about $2 \mathrm{~cm}$ to guarantee the primary donor site closure. Zone A, with a length equal to the diameter of the UCF, was designed to flip over to form the urethral layer. Zone B, with a length between half and full diameter of the UCF, was designed to fold for waterproof layer formation. Zone $\mathrm{C}$, with a length 1.5 times the diameter of the UCF, was designed to extend to form the cutaneous coverage.

The whole flap was then raised distally to proximally within the dartos fascia layer. The pedicle vessels could be clearly seen within the dartos fascia, and was pushed upwards and skeletonized to obtain sufficient length for flap transfer. Zone A was flipped over to cover the urethral defect of the UCF by an inverting, subcuticular stitching to the urethral layer (Fig. 1, part B). Zone B was de-epithelialized, folded and stitched to the dartos fascia around UCF (Fig. 1, part C). Zone C was extended over the dartos layer with its skin covering the cutaneous defect as an advancement flap (Fig. 1, part C), namely the dartos of zone B was folded twice to form a double waterproof layer. Finally, the donor site was closed directly (Fig.1, part D).

As a support, a porous silicone support tube and a $6 \mathrm{~F}$ silicone urinary catheter were introduced into the bladder. Then, a double-layer, elasticated tubular bandage was used to pressure the flap to promote tissue healing. The "scrotum prop" (Fig. 2) was used to reduce tension on the flap. The urinary catheter was withdrawn after 3 to 5 days, and the urethral support tube was preserved 10 to 14 days after surgery.

\section{Results}

The skin flaps survived and the incisions healed in 28 patients. In one case, the zone $\mathrm{C}$ of the flap had venous

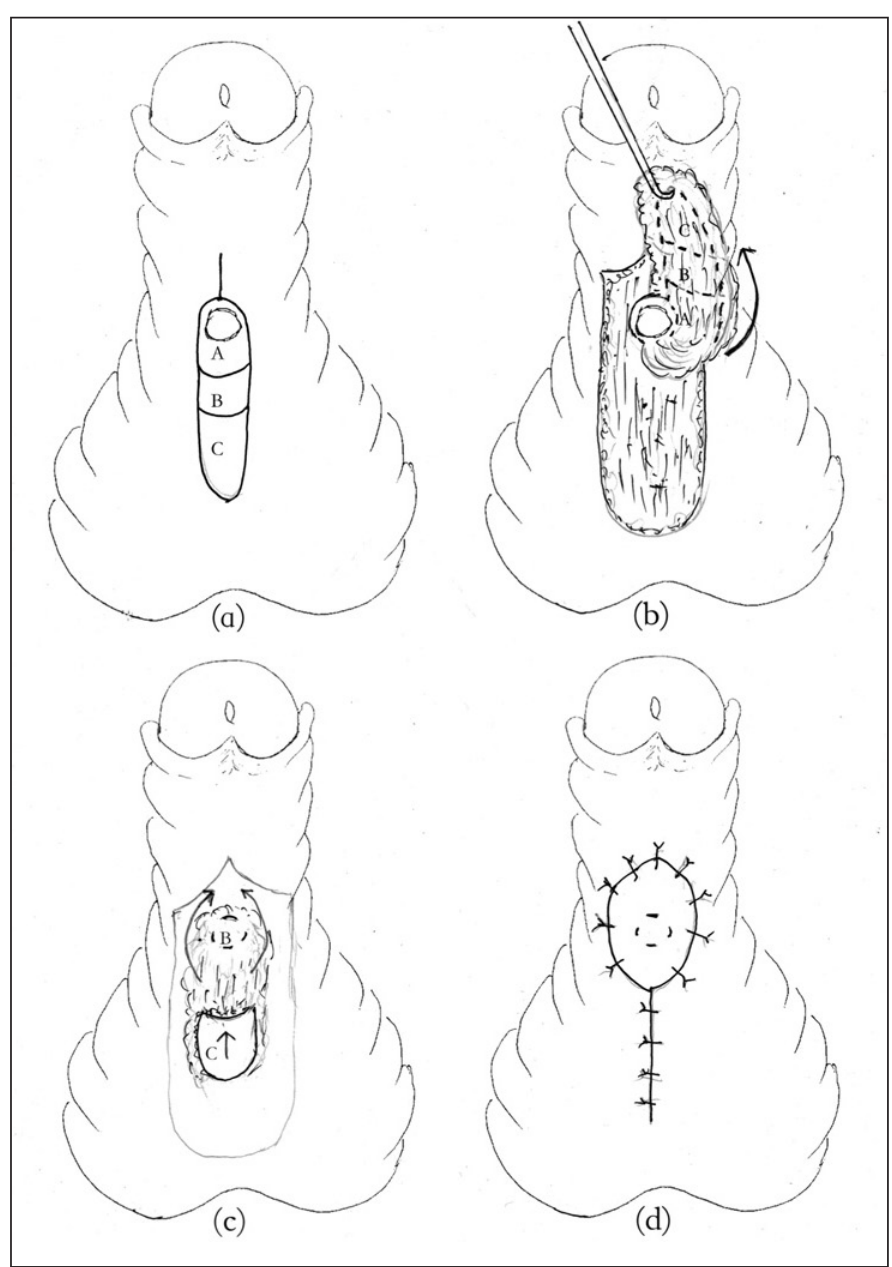

Fig. 1. A: Design of the surgical incisions and zones. B: Zone $A$ is turned over to cover the urethrocutaneous fistulas and form the urethra layer. C: Zone $B$ without epidermis is folded to form a double waterproof layer. Zone $C$ is advanced to cover the wound. D: The donor site is sutured directly.

congestion and was eventually lost (Fig. 3, part A, B). In total, 29 patients were followed between 6 to 12 months, with a mean of 9.4 months. All patients showed smooth urination. No fistula recurrence was observed. The patient with zone $\mathrm{C}$ problems showed scarring of the scrotal skin flap, but voided well without obvious stenosis (Fig. 3, part C). As zones A, B, and C of the flap all covered the UCFs, the penoscrotal junction had a slightly bloated appearance, and 2 patients were not satisfied with the local appearance. At 6 and 13 months, respectively, these 2 patients underwent ventral penis elongation to reshape the penis scrotal angle.

\section{Discussion}

The most troublesome complication of hypospadias repair is UCF due to the lack of healthy surrounding tissue. When the diameter of the UCF is larger than $1 \mathrm{~cm}$, local tissue is not sufficient for multiple-layer reconstruction, especially in 


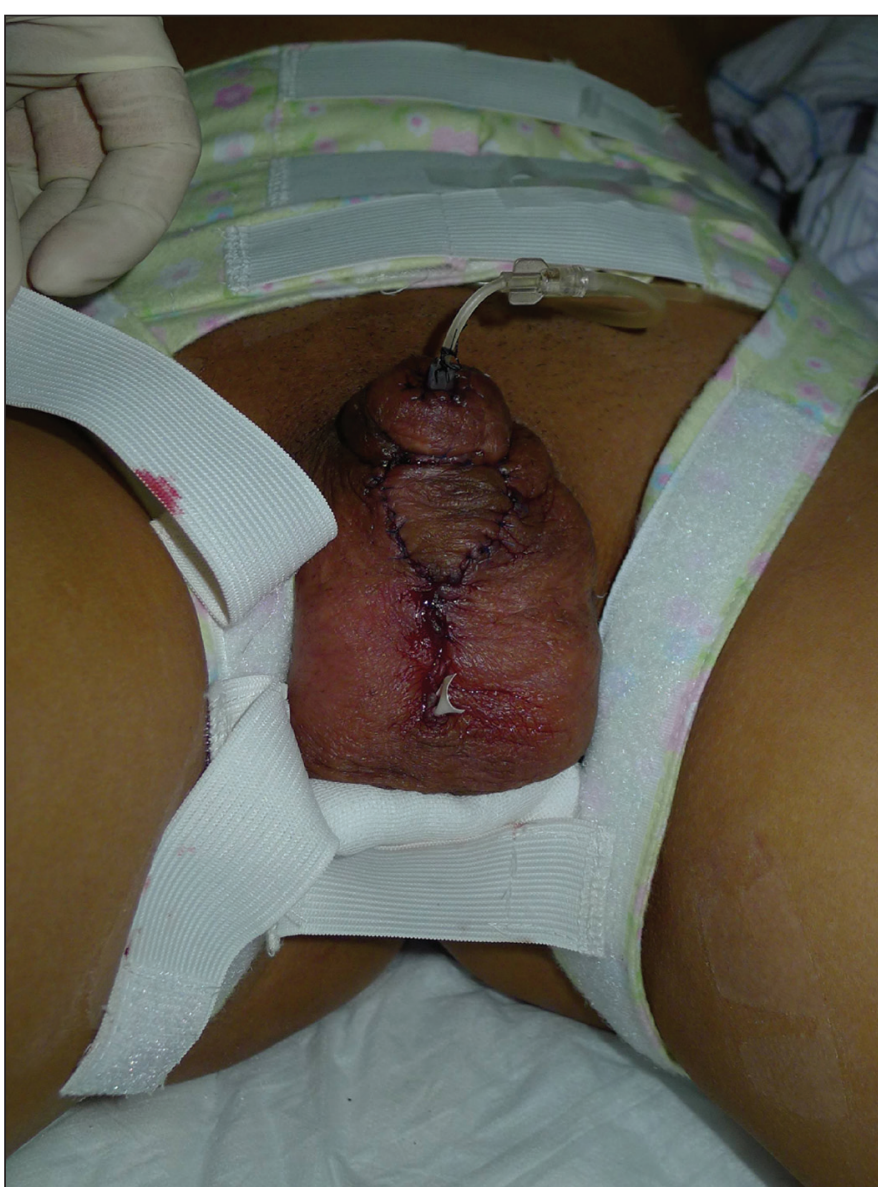

Fig. 2. The "scrotum prop," there are 3 elastic cords to holding the scrotum for reducing tension on the flap.

patients with a history of previous repeated repairing surgeries. In such circumstances, a repair of the large UCF usually requires application of regional skin and fascial flaps with good blood supply to reconstruct three layers, including an outer cutaneous coverage, an inner urethral layer, and a waterproof interlayer.

Most techniques described to repair of UCFs in the last 3 decades have focused on providing a multilayered closure. Usually, the fistulous tract is circumscribed, dissected and closed to form the urethral layer by suture or sealant. ${ }^{11}$ Local fascial tissue around the UCF, such as a de-epithelialized scrotal advancement flap, ${ }^{3,4}$ a pure dartos flap or a tunica vaginalis flap, was transferred to form an effective vascularized waterproof barriers..$^{5-8}$ Then a preputial or scrotal flap was transferred to cover the cutaneous wound. The three layers are fabricated using different tissues from different flaps, which make the procedure complex and time-consuming.

The scrotal-septal fasciocutaneous flap is an axial island skin flap, whose vascular pedicle is composed of the anterior and posterior scrotal arteries and their anastomotic branch. ${ }^{12}$ The posterior scrotal artery originates from the internal

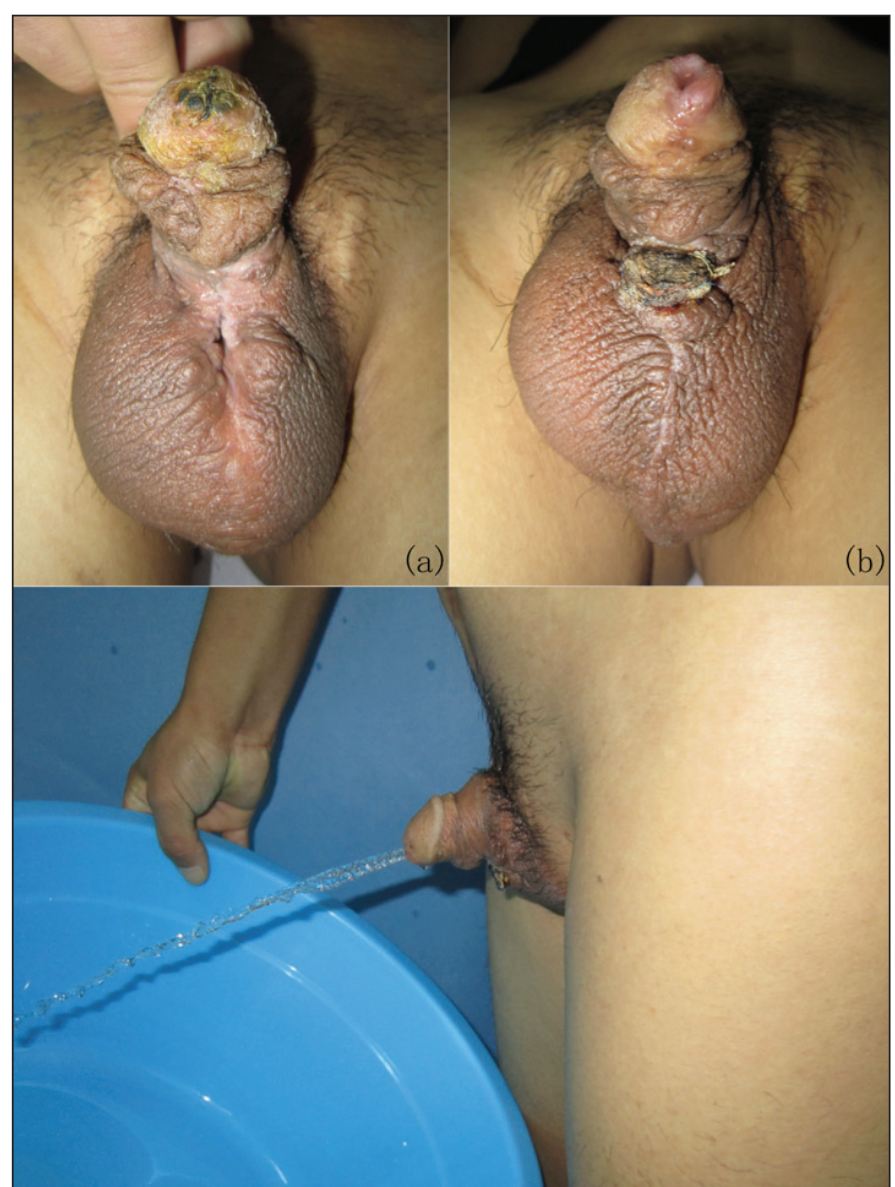

Fig. 3. A: An 18-year-old man, scrotal hypospadias, had undergone two-stage hypospadias repair and 2 urethrocutaneous fistulas repair surgeries. B: The zone $\mathrm{C}$ of the flap turned black and was eventually lost to dry necrosis at 15 days postoperatively. $C$ : The patient with zone $C$ problems showed scarring of the scrotal skin flap, but voided well.

pudendal artery, and the anterior artery from the external pudendal artery. The medial branch of the two arteries penetrates the scrotal septum from its lower and upper sides. The anterior artery supplies the upper two-thirds of the skin tissue of scrotal septal skin flap, and the posterior scrotal arteries supplies the lower one-third of the scrotal septal skin flap. These vessels have branches that join together. Moreover, the flap has great tissue volume and can be harvested without scrotum disfiguration. Since the flap has the advantages of a rich blood supply and abundant amount of tissue, we improved the design and used one fasciocutaneous flap to reconstruct three layers in one stage.

"Using one flap for multiple purposes" simplified the procedures, saved the operative time, and minimized the donor site morbidities. The operative time ranged from 90 to 160 minutes, with a mean of 125 minutes. With the increase of proficiency, the operative time is shorter. We found that a long narrow scrotal-septal flap with 4:1 length:width ratio can be raised reliably. Thus, the flap can be divided into three portions and used for multiple layer reconstruction. 
Meanwhile, its long fascial pedicle allows great flexibility of the flap transfer, which ensures that the flap can be flipped over without tension. Flap folding is a common way for double-layer reconstruction, such as in repairing buccal penetrating defects. Using this technique, the zone B flap was folded twice to form double layers of dartos tissue, as a reliable waterproof barrier between urethra and skin. In this series, there was no evidence of UCF recurrence.

Scrotal-septal skin flap has its inherent disadvantages. Hair growth of the zone A flap in the urethra will potentially lead to urethral stricture and urinary tract stone formation after surgery. To solve this problem, we destroyed the hair follicles in the scrotal-septal area using a radiosurgical knife 2 months before surgery, which effectively prevented the above complications. Although the scrotal-septal flap contained a known artery and veins, the double folding might compromise the blood supply to the flap, especially the venous drainage of the distal portion. In one case, dry necrosis of zone $\mathrm{C}$ occurred due to the venous congestion. However, no recurrence of UCFs or stenosis happened 3 months later. We thought this was because the thick middle layer resisted the scar contracture and guaranteed the complete seal of the fistula. Moreover, the 28 flaps survived totally without venous congestion. Certainly, hair growth and stenosis have been well-described and increase with time ( $>5$ years). We will be following up on our patients to evaluate the effectiveness of the flaps.

This method has its limitations. The width of the flap $(<2.0 \mathrm{~cm})$ guarantees a tension-free donor site closure and preserves the scrotum aesthetic contour. Thus, this method is not suitable to repair UCFs with a diameter exceeding $2.0 \mathrm{~cm}$. The UCFs distal to the penoscrotal junction is out of reach of the aone A flap and cannot be repaired using this technique. It cannot be used in patients with a damaged scrotal septum obviously. The penoscrotal junction will have a bloated appearance and patients concerned with the aesthetic outcome may need secondary refinement procedures to reshape the penis scrotal angle.

\section{Conclusion}

With sufficient blood supply and tissue volume, the scrotal-septal flap can be transferred in an overturning-foldingadvancement fashion and can simultaneously involve the reconstruction of the urethra, waterproof barrier and skin coverage. This technique greatly simplifies the procedure and saves the operative time. It is a good option for the repair of large UCFs less than $2 \mathrm{~cm}$ at the penoscrotal junction.

Competing interests: Dr. Y. Zhou, Dr. L. Li, Dr. C. Zhou, Dr. F. Li, Dr. Xie and Dr. S. Li all declare no competing financial or personal interests.

This paper has been peer-reviewed.

\section{References}

1. Lambert SM, Snyder HM 3' Canning DA. The history of hypospadias and hypospadias repairs. Urology 2011;77:1277-83. http://dx.doi.org/10.1016/i.urology.2010.10.031

2. Prat $D$, Natasha A, Polak A, et al. Surgical outcome of different types of primary hypospadias repair during three decades in a single center. Urology 2012;79:1350-3. http://dx.doi.org/10.1016/i. urology.2011.11.085

3. Lee SE, Kim KM, Kim YK. De-epithelialized scrotal flap in repair of urethrocutaneous fistula and hypospadias. Urology 1990;36:160-3. http://dx.doi.org/10.1016/0090-4295(90)80217-B

4. Ahuja RB. A de-epithelialised 'turnover dartos flap' in the repair of urethral fistula. J Plast Reconstr Aesthet Surg 2009;62:374-9. http://dx.doi.org/10.1016/i.bips.2008.03.031

5. Józsa T, Cśizy I, Csiszkó A, et al. Double unfurled dartos flap technique in the surgical treatment of recurrent urethrocutaneous fistulas. Urol Int 201 1;87:380-4. http://dx.doi.org/10.1159/000329776

6. Snow BW, Cartwright $P C$, Unger K. Tunica vaginalis blanket wrap to prevent urethrocutaneous fistula: An 8-year experience. J Urol 1995;153:472-3. http://dx.doi.org/10.1097/00005392-19950200000061

7. Kadian YS, Rattan KN, Singh J, et al. Tunica vaginalis: An aid in hypospadias fistula repair: Our experience of 14 cases. Afr J Paediatr Surg 2011;8:164-7. http://dx.doi.org/10.4103/0189-6725.86054

8. Sharma N, Baipai $M$, Panda SS, et al. Tunica vaginalis flap cover in repair of recurrent proximal urethrocutaneous fistula: A final solution. Afr J Paediatr Surg 2013;10:31 1-4. http://dx.doi.org/10.4103/01896725.125421

9. Li SY, Li SK, Zhuang HX. The use of scrotal septal neurovascular pedicle island skin flap in one-stage repair of hypospadias. Ann Plast Surg 1985;15:529-33. http://dx.doi.org/10.1097/00000637198512000-00012

10. Liu $X$, Li Y, Li S, et al. A new use of scrotal septal skin flap in repairing hypospadias. Ann Plast Surg 2011;67:164-6. http://dx.doi.org/10.1097/SAP.0b013e3181cc2aal

11. Kaibafzadeh AM, Abolghasemi H, Eshghi P, et al. Single-donor fibrin sealant for repair of urethrocutaneous fistulae following multiple hypospadias and epispadias repairs. J Pediatr Urol 201 1;7:422-7. http:// dx.doi.org/10.1016/i.jpurol.2010.06.004

12. Carrera A, Gil-Vernet A, Forcada $\mathrm{P}$, et al. Arteries of the scrotum: A microvascular study and its application to urethral reconstruction with scrotal flaps. BJU Int 2009; 103:820-4. http://dx.doi.org/10.1111/i.1464410X.2008.08167.x

Correspondence: Dr. Senkai Li, Department of Hypospadias and Gynecological Plastic Surgery, Plastic Surgery Hospital, Peking Union Medical College, Ba-Da-Chu Road, 33\#, Shi-jing-shan District, Beiing, China. 100144; drlisk@yahoo.com 